Kajian Ilmiah Mata Kuliah Umum

Volume 15 Nomor 1, September 2015

Penerbit
Pelindung dan Penasehat
Penanggung Jawab
Pemimpin Umum
Penyunting Ahli
Pemimpin Redaksi
Sekretaris Redaksi
Anggota Redaksi

Sekretariat
: Pusat MKU Universitas Negeri Yogyakarta

: Wakil Rektor I UNY

: Wawan S. Suherman

: Sunarso

: Marzuki

: Rukiyati

: Vita Fitria

: Sri Agustin Sutrisnowati, Amir Syamsudin, Syukri Fathudin Achmad Widdodo,

Benni Setiawan

: Ari Saraswati

Alamat Redaksi/Tata Usaha:
Pusat MKU UNY, Gedung LPPMP Lt.3 Sayap Timur
Kampus Karangmalang Yogyakarta
Email: mku@uny.ac.id, mku.uny@gmail.com, ruki1961@yahoo.com

HUMANIKA Kajian Ilmiah Mata Kuliah Umum menerima kiriman tulisan/artikel yang terkait dengan Mata Kuliah Umum (MKU), yang meliputi Pendidikan Agama, Pendidikan Pancasila, Pendidikan Kewarganegaraan, Ilmu Sosial Dasar, Ilmu Budaya Dasar, Ilmu Alamiah Dasar, dan Pendidikan Kependudukan dan Lingkungan Hidup, dengan ketentuan sebagai berikut:

1. Naskah dapat berupa hasil penelitian atau artikel ilmiah bebas dan belum pernah diterbitkan.

2. Naskah diketik dengan spasi satu setengah (1,5 spasi) dengan jumlah halaman 1015 halaman kuarto, diketik dengan MS Word ukuran font 12 Times New Roman.

3. Naskah memuat komponen: judul ( $<10 \mathrm{kata})$, nama penulis, alamat email, abstrak (100-150 kata), isi karangan (yang memuat pendahuluan, pembahasan, kesimpulan) dan daftar pustaka.

4. Naskah dikirim dalam bentuk print out dan soft copy.

5. Daftar pustaka ditulis secara alfabetis seperti berikut:

- Hidayat, Komaruddin. 2004. Menafsir Kehendak Tuhan. Jakarta: Serambi.

- Bagir, Haidar. 2012. "Syiah dan Kerukunan Umat". Republika. 20 Januari. 


\section{DAFTAR ISI}

Redaksi Humanika ........................................................................... i

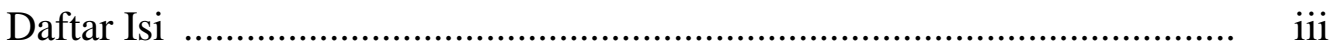

Pengantar Redaksi ...........................................................................

Islam Rahmah dan Wasathiyah

(Paradigma Keberislaman Inklusif, Toleran dan Damai)

Abd. Malik Usman........................................................................... 1-12

The Dialectics of Javanese and Islamic Cultures:

an Introduction to Kuntowijoyo's Thought

Pradana Boy ZTF

Persepsi Masyarakat Kotagede Terhadap Pengunaan Media Komunikasi oleh Organisasi Forum Joglo untuk Peletarian Budaya di Kotagede

Yogyakarta

Choirul Fajri

Implikasi Budaya Organisasi Terhadap Pola Perilaku Komunikasi

Kelompok Tani Sumber Rejeki

Mariana Ulfah dan Siti Chotijah

Etika Sosial dalam Kerukunan Umat Beragama

(Studi Kasus di Desa Kotesan Kecamatan Prambanan Kabupaten Klaten

Jawa Tengah)

Andy Dermawan dan Zunly Nadia

Model Komunikasi "Wom" Sebagai Strategi Pemasaran Efektif

Dani Fadillah

Mencari Model Pendidikan Karakter

Suparlan 


\title{
ISLAM RAHMAH DAN WASATHIYAH (Paradigma Keberislaman Inklusif, Toleran dan Damai)
}

\author{
Oleh: \\ Abd. Malik Usman \\ Universitas Gadjah Mada \\ el_usmani@yahoo.co.id
}

\begin{abstract}
.
Islamic doctrines that brings mercy for the worlds (rahmatan lil'alamien) and its adherents as moderate people (ummatan wasathan) as well as the best people is the basis for the realization of the attitudes and behavior of Islam which is humanist, inclusive, tolerant and peaceful. In the context Indonesia that it is pluralistic society in the field of customs, language, culture and even religion, Islam people (muslim) as the majority must perform as best people who are capable as grace and a paste for the plurality of Indonesian and to lead them for reaching prosperity for all mankind.
\end{abstract}

Keywords : Islam, inclusive, grace, moderate, plurality.

\begin{abstract}
Abstrak
Doktrin Islam sebagai agama yang membawa rahmat buat semesta alam

(rahmatan lil'alamien) dan penganutnya sebagai ummatan wasathan (umat tengah tengah/ moderat) serta umat terbaik adalah dasar bagi terwujudnya sikap dan perilaku berislam yang humanis, inklusif toleran dan damai. Dalam konteks keindonesiaan yang nota bene masyarakatnya sangat majemuk (heterogen-pluralistik) dalam bidang adat istiadat, bahasa, budaya bahkan agama, maka Islam rahmatan dan wasathan dan didukung pula dengan posisi umatnya sebagai umat mayoritas penduduk negeri ini, sejatinya harus tampil sebagai kekuatan perekat sekaligus menjadi pelindung "memayu hayuning bawono" agar kebinekaan dan pluralitas dapat menjadi rahmat dan barokah dalam rangka fastabiqul khairat untuk kesejahteraan seluruh umat manusia.
\end{abstract}

Kata kunci : Islam, inklusif, rahmah, moderat, kemajemukan.

\section{PENDAHULUAN}

Topik Islam rahmah dan
wasathiyah menarik bahkan cukup
urgen untuk diperbincangkan dan
disebarluaskan ke khalayak umat
beragama, khususnya umat Islam, dan
lebih khusus lagi umat Islam Indonesia.
Alwi Shihab (2001:3) mengatakan jika
dilihat dari sudut pandang geologis,
historis dan kultural, Indonesia adalah

negara yang sangat kompleks dengan keragaman ras, suku bangsa, bahasa

bahkan agama. Oleh karena itu, cukup beralasan, jika para the founding fathers kita mencanangkan semboyan Bhineka Tunggal Ika (berbeda-beda tetapi tetap satu) untuk merekatkan persatuan bangsa.

Filosofi atau nilai idealisme yang terbangun dari semboyan tersebut 
adalah mengandaikan terciptanya suasana kedamaian di tengah keberagaman, suasana rukun dalam berinteraksi yang dialogis di atas perbedaan. Hal ini tidak dapat dipungkiri karena merupakan fakta sosial yang tak terbantahkan dan sebuah karunia Tuhan buat bangsa kita.

Secara empiris-historis dapat dikatakan bahwa jauh sebelum kedatangan awal Islam pada abad ke 8 $M$ dan berkembang pesat sejak abad ke 13 M, agama Kristen Protestan maupun Katolik pada abad ke 16 M, masyarakat Indonesia dan Nusantara telah lama menganut kepercayaan animisme dan dinamisme, lalu Hindu dan Budha dengan bukti bukti historis-arkeologis seperti candi, arca dan lain lain di pulau Jawa dan luar Jawa. Proses masuk dan berkembangnya Islam di Nusantara menurut Amin Abdullah (2002:5) berlangsung secara masif dengan jalan damai, dan inilah sebuah prestasi sejarah yang amat mengagumkan. Hasilnya mayoritas penduduk Indonesia adalah muslim dan selebihnya yakni 15$18 \%$ adalah non muslim. Posisi mayoritas ini memiliki keunikan tersendiri yang dibukti-kan dengan kemampuannya hidup ber-dampingan dan beradaptasi dengan umat agama lain. Keunikan ini juga turut mempengaruhi penghayatan dan pengalaman kolektif umat Islam terhadap pluralitas agama maupun budaya lokal (kearifan lokal) Indonesia. Inilah bukti keunikan umat Islam Indonesia yang tidak dimiliki oleh umat Islam di negeri negeri timur tengah yang mengklaim dirinya sebagai negara Islam.
Seiring perjalanan waktu terutama penghujung abad $20 \mathrm{M}$ hingga abad 21 $\mathrm{M}$ ini, keunikan yang merupakan ciri dan karakter muslim Indonesia yang mengedepankan toleransi, sikap terbuka terhadap kebinekaan maupun kemajemukan mulai bergeser. Sejumlah fakta tentang konflik dan kekerasan yang dilakukan oleh individu maupun kelompok dengan mengatasnamakan agama bahkan dengan dalih membela agama telah merusak kebhinekaan dan toleransi itu sendiri. Hal ini mengundang pertanyaan besar: Apakah betul mereka membela agama? Apakah Tuhan menurunkan agama kepada manusia untuk berkonflik? Jawabannya tentu tidak, karena agama bahkan semua agama pada dasarnya membawa pesan damai atau misi perdamaian untuk umat manusia semesta. Konflik atau kekerasan atas nama agama dan membela agama menjadi bukti nyata bahwa agama telah dialihfungsikan bahkan diselewengkan oleh umatnya. Oleh karena itu, konflik maupun kekerasan tersebut sesungguhnya adalah tindakan anti agama bahkan "penistaan agama" (dalam makna substansial). Sebab, agama agama itu pada hakikatnya memiliki ciri ciri fundamental-esensial dan menonjol yaitu spiritualitas. Bagaimana konsep Islam sebagai agama yang penuh rahmah dan bersifat washatiyah? Pertanyaan tersebut akan diJawab dalam tulisan berikut ini.

\section{PEMBAHASAN}

\section{Makna Islam Rahmatan}

Islam sebagai agama rahmatan lil 'alamien dan wasathiyah (moderat) 
sesungguhnya sangat kaya dengan spiritualitas Ilahiyah yang berimplikasi pada sikap hidup yang humanis, inklusif, toleran dan damai (menebar kedamaian) pada tataran sosial umat atau dikenal dengan doktrin hablun minannas. Allah berfirman di dalam Alquran, Surat Al-Anbiyaa ayat 107 sebagai berikut.

$$
\text { ومآ ارسلناك الا رحمة لعالمين }
$$

"Dan tiadalah Kami mengutus kamu (Muhammad) melainkan sebagai pembawa rahmat bagi semesta alam".

Kata kunci ayat di atas adalah rahmat (الزّحمة). Dalam Lisan al-Arab (الرّحمة) (1086) makna ar-Rahmah) adalah: ar-Ruqqah wa at-Ta'aththuf (الرقة والتعطف) yaitu "kelembutan yang terpadu dengan rasa iba (kasih sayang). Jadi diutusnya Nabi Muhammad SAW, adalah wujud kasih sayang Tuhan kepada seluruh umat manusia.

Kata rahmat (رحمة) ditafsirkan secara beragam oleh ulama-ulama tafsir antara lain:

1. Tafsir Ibnul-Qoyyim al-Jauziyah via Yulia Purnama (muslim.or.id/Alquran lisanrahmatan lil-alamin.html.) bahwa semesta raya mendapat manfaatnya dengan diutusnya Muhammad Saw, dan orang-orang yang mengikuti beliau dapat meraih kemuliaan dunia akhirat. Oleh karena itu, orang-orang munafik dan non muslim pun mendapat manfaat berupa terjaga darahnya, hartanya, keluarga dan kehormatannya, serta memperoleh perlakuan sama dengan kaum muslimin. Jadi, Islam adalah rahmat buat semua, namun buat orang beriman, akan mendapat manfaat dunia dan akhirat, sedang yang menolak atau mengingkarinya, tidak mengurangi nilai rahmat sedikitpun.

2. Dalam Fathul Qadir, Muhammad bin Ali as-Syaukany (tt : 419) menafsirkan bahwa satu-satunya alasan Allah mengutus Nabi Muhammad Saw adalah sebagai rahmat yang luas, karena Allah mengutusnya dengan membawa sesuatu yang menjadi sebab kebahagiaan dunia-akhirat.

3. Muhammad bin Jarir at-Thabary (1992: 92) menafsirkan bahwa rahmat itu buat semua (mukmin dan kafir) seperti riwayat Ibn Abbas:

$$
\begin{aligned}
& \text { من امن بالله و اليوم الاخر كتب له الرحمة }
\end{aligned}
$$

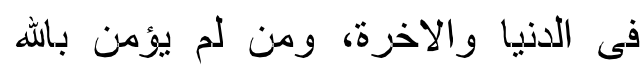

$$
\begin{aligned}
& \text { ورسوله، عوفى مما اصاب الامم من ومن لأمن باله } \\
& \text { الخسف و الغرق/ و القذف لهوف }
\end{aligned}
$$
kepada Allah dan hari akhir, ditetapkan baginya rahmat di dunia dan di akhirat. Namun siap saja yang teridak beriman, bentuk rahmat buat mereka adalah dengan tidak ditimpa musibah, sebagaimana pernah menimpa umat terdahulu berupa "ditenggelamkan atau ditimpa gelombang besar".

Masih terdapat sejumlah riwayat lain yang redaksinya sedikit beda tetapi sama maknanya, seperti yang dikutip oleh al-Qurthuby dalam tafsirnya (1993: 255) bahwa Nabi Muhammad Saw bersabda:

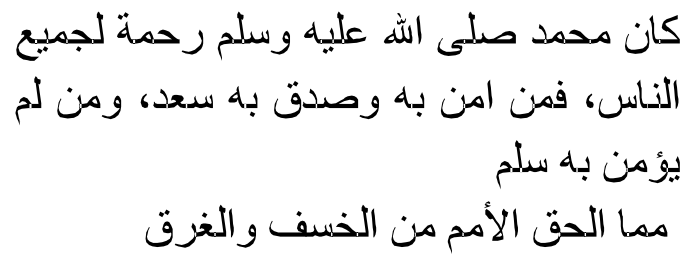




\section{"Bahwa Rasulullah Muhammad} $S A W$, adalah rahmat bagi seluruh umat manusia, maka barangsiapa yang beriman dan membenarkannya, dijamin bahagia dan barang siapa yang tidak beriman dengannya, diselamatkan (memperoleh keselamatan) dari musibah berupa ditenggelamkan di dalam bumi dan air, seperti umat-umat terdahulu".

As-Shabuny dalam Sofwatu atTafasir (1981: 277) mengutip sebuah hadis pendek yang diriwayatkan alBukhary .... إنما أنا رحمة مهداة..... "bahwasanya saya adalah rahmat yang dihadiahkan".

Untuk memperkuat pandanganpandangan di atas, dapat dikemukakan pendapat Ibn. Abbas bahwa "Allah SWT mengutus Muhammad Saw adalah rahmat bagi seluruh manusia (mukmin dan kafir). Bagi mukmin Allah memberinya petunjuk dengan sebab diutusnya Muhammad Saw, dan memasukkan mereka ke surga karena iman dan amal saleh. Sedangkan rahmat bagi si kafir berupa tidak disegerakannya bencana menimpa mereka seperti yang terjadi pada umat terdahulu yang mengingkari ajaran Allah SWT".

Dengan demikian dapat disimpulkan bahwa Islam benar-benar sebagai agama yang membawa rahmat bagi seluruh umat manusia, baik yang mukmin maupun yang kafir.

\section{Makna Islam Wasathan-Wasathiyah}

Istilah wasathan secara bahasa menurut A.W Munawwir (1997:1557) diambil dari istilah wasatha, wustha yang bermakna tengah, dan menjadi istilah wasith- alwasith artinya penengah. Istilah ini menurut Fuad
Abdul Baqy' (1981:750) hanya sekali disebut dalam Alquran yakni QS.2-alBaqarah: 143, di samping istilah lain seperti: wasathna, ausathi, ausathuhum dan alwustha. Oleh karena itu di dalam studi 'ulumul-qur'an disebut 'ilmu ghoriebi Alquran yakni ilmu tentang kata atau istilah-istilah asing di dalam Alquran.

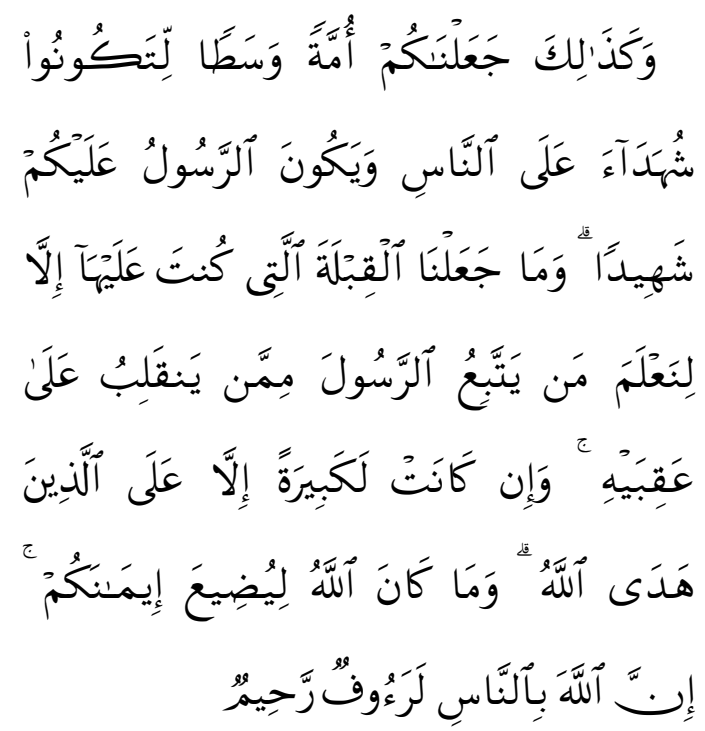

Dan demikian (pula) kami Telah menjadikan kamu (umat Islam), umat yang adil dan pilihan agar kamu menjadi saksi atas (perbuatan) manusia dan agar Rasul (Muhammad) menjadi saksi atas (perbuatan) kamu. dan kami tidak menetapkan kiblat yang menjadi kiblatmu (sekarang) melainkan agar kami mengetahui (supaya nyata) siapa yang mengikuti Rasul dan siapa yang membelot. dan sungguh (pemindahan kiblat) itu terasa amat berat, kecuali bagi orang-orang yang Telah diberi petunjuk oleh Allah; dan Allah tidak akan menyia-nyiakan imanmu.

Sesungguhnya Allah Maha Pengasih lagi Maha Penyayang kepada manusia.

Istilah umatan wasathan dalam ayat di atas ditafsirkan oleh Quraish 
Shihab (2002:347) yakni umat pertengahan, moderat dan tauladan. Keberadaan umat Islam pada posisi pertengahan itu sesuai dengan posisi Ka'bah yang berada di pertengahan pula. Posisi ini menjadikan manusia tidak memihak ke kiri dan ke kanan, suatu posisi dimana dapat mengantar manusia berlaku adil. Posisi pertengahan menjadikan seseorang dapat dilihat oleh siapapun dalam penjuru yang berbeda, dan ketika itu ia dapat menjadi tauladan bagi semua pihak. Posisi itu juga menjadikannya dapat menyaksikan siapa pun dan dimana pun. Ada juga makna lain tentang umatan wasathan, lanjut Quraish Shihab (2002:347) yaitu pertengahan dalam pandangan tentang Tuhan dan dunia, tidak mengingkari wujud Tuhan, tetapi tidak juga menganut paham politeisme (banyak Tuhan). $\quad . . \quad$ Pertengahan juga mengandung makna bahwa pandangan umat Islam tentang kehidupan dunia ini tidak diingkari dan dinilai maya, tetapi juga tidak berpandangan bahwa kehidupan dunia adalah segalanya. Pandangan Islam tentang hidup adalah di samping ada dunia, ada juga akhirat, tidak tenggelam dalam materilaisme, tidak juga membumbung tinggi dalam spiritualisme. Ketika pandangan mengarah ke langit, kaki harus tetap berpijak di bumi. Islam mengajarkan umatnya agar meraih materi yang bersifat duniawi, tetapi dengan nilainilai samawi.

Yusuf Al-Qardhawi (1996:101) menyatakan pertengahan sebagai altawazun (keseimbangan), yakni keseimbangan antara dua jalan atau dua arah yang saling berhadapan atau bertentangan: ruhiyah (spiritualisme) dengan maddiyah (materialisme); fardiyah (individu) dengan jamaiyah (kolektif); waqi'iyah (kontekstual) dengan mitsaliyah (idealisme); tsabat (konsisten) dengan taghayyur (perubahan). Oleh karena itu keseimbangan (al-tawazun) lanjut AlQardhawi; sesungguhnya merupakan watak alam raya (universum) sekaligus menjadi watak dari Islam sebagai risalah abadi. Bahkan, amal menurut Islam bernilai saleh, jika amal itu diletakkan dalam prinsip-prinsip keseimbangan antara hablun minallah dan hablun minannaas.

Di atas prinsip keseimbangan inilah, Islam sebagai hudan (pedoman hidup) telah membimbing umatnya keluar dari kegelapan menuju cahaya dan mengantarnya menggapai kemajuan dan kejayaan. Ibnu Katsir dalam kitabnya Jami'ul Bayan (Khaerul Wahidin, 1987:62) mengatakan istilah umatan wasathan bermakna sebagai kemampuan-kemampuan positif yang dimiliki umat Islam sebagaimana dalam kurun pertama sejarahnya yakni dalam capaian-capaian kemajuan di bidang material maupun spiritual.

Sudah menjadi fakta sejarah yang tak terbantahkan menurut Khaerul Wahidin (1987:63) bahwa negeri Arab sebelum kedatangan Islam merupakan tempat tinggal para kabilah dan sukusuku bangsa yang saling berperang satu dengan lainnya. Jalan hidupnya penuh kesesatan dan kemaksiatan, perilakunya penuh dengan dosa dan kenistaan sehingga masyarakat dunia menyebutnya sebagai bangsa Jahiliah. Dalam tempo yang singkat mereka menjadi bangsa yang bersatu, berdamai 
dan memadukan cita dan rasa sehingga menjadi bangsa yang terhormat dan dikagumi. Bahkan hanya lebih dari satu abad sesudah wafatnya Nabi Muhammad Saw, dunia Islam menurut Albert Hourani (2004:bab.I) tampil sebagai sebuah imperium (baca: peradaban) yang sangat berpengaruh di Barat maupun di Timur. Era inilah dikenal dengan sebutan The Golden Age of Islam (Masa Keemasan Islam). Fakta sejarah ini menguatkan ayat Alquran di atas, yakni:

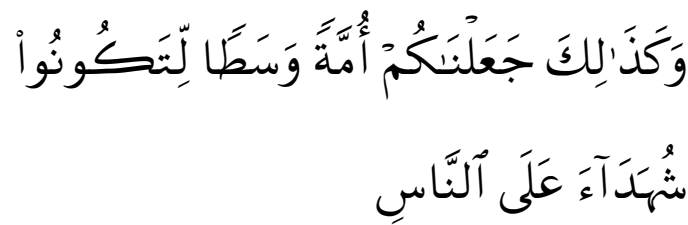

"Dan demikian Kami telah menjadikan kamu, ummatan wasathan (umat pertengahan) agar kamu menjadi saksi atas perbuatan manusia..."

Kemunculannya sebagai pencipta perikemanusiaan dan peradaban, tangguh, berwibawa dan disegani, juga sebagai bangsa yang telah meraih capaian-capaian peradaban besar yang memberikan manfaat bagi kemanusiaan di muka bumi, sebagaimana pengakuan jujur seorang orientalis bernama W. Montgomery Watt (1984:bab.9) pada bagian akhir tulisannya yang sangat populer dalam bukunya yang berjudul "Muhammad Prophet and Statesman".

\section{Islam Rahmah dan Wasathiyah (Islam Inklusif, Humanis dan Toleran)}

Dalam salah satu hadis sahih dinyatakan "Aku diutus dengan menyebarkan agama yang toleran". Hadis ini menjadi dasar bahwa Islam adalah agama toleran, agama hanif yang mengajarkan sikap lapang dada. Secara geneologis, kehanifan (al-Hanafiyah) adalah agama yang dibawa oleh Nabi Ibrahim as, sebagaimana disebutkan dalam Alquran yakni sebagai agama yang lurus, toleran dan berserah diri kepada Tuhan secara total (hanifan musliman). Bahkan Nabi Ibrahim as meminta kepada Tuhan agar Ismail, Ishak dan keturunannya menjadi nabinabi yang mengamalkan ajaran tersebut yakni tunduk, patuh dan berserah diri kepada Tuhan (QS. 2: 128-133):

128. Ya Tuhan kami, jadikanlah kami berdua orang yang tunduk patuh kepada Engkau dan (jadikanlah) diantara anak сиси kami umat yang tunduk patuh kepada Engkau dan tunjukkanlah kepada kami cara-cara dan tempat-tempat ibadat haji kami, dan terimalah Taubat kami. Sesungguhnya Engkaulah yang Maha Penerima Taubat lagi Maha Penyayang.

129. Ya Tuhan kami, utuslah untuk mereka sesorang Rasul dari kalangan mereka, yang akan membacakan kepada mereka ayatayat Engkau, dan mengajarkan kepada mereka Al Kitab (Al Quran) dan Al-Hikmah (AsSunnah) serta mensucikan mereka. Sesungguhnya Engkaulah yang Maha Kuasa lagi Maha Bijaksana.

130. Dan tidak ada yang benci kepada agama Ibrahim, melainkan orang yang memperbodoh dirinya sendiri, dan sungguh kami Telah memilihnya di dunia dan Sesungguhnya dia di akhirat benar-benar termasuk orangorang yang saleh.

131. Ketika Tuhannya berfirman kepadanya: "Tunduk patuhlah!" 
Ibrahim menJawab: "Aku tunduk patuh kepada Tuhan semesta alam".

132. Dan Ibrahim telah mewasiatkan ucapan itu kepada anak-anaknya, demikian pula Ya'qub. (Ibrahim berkata): "Hai anak-anakku! Sesungguhnya Allah Telah memilih agama Ini bagimu, Maka janganlah kamu mati kecuali dalam memeluk agama Islam".

133. Adakah kamu hadir ketika Ya'qub kedatangan (tanda-tanda) maut, ketika ia Berkata kepada anak-anaknya: "Apa yang kamu sembah sepeninggalku?" mereka menJawab: "Kami akan menyembah Tuhanmu dan Tuhan nenek moyangmu, Ibrahim, Ismail dan Ishaq, (yaitu) Tuhan yang Maha Esa dan kami Hanya tunduk patuh kepada-Nya".

Ayat yang senada dan hampir sama maknanya cukup banyak dijumpai di dalam Alquran, oleh karena itu tidak salah jika dikatakan bahwa Alquran adalah kitab suci yang paling toleran. Freedmann (2003:1) menyatakan bahwa, walau memang tidak ada kata (istilah) toleransi-al-tasamuh secara eksplisit dalam Alquran, tetapi jika yang dimaksud dengan toleransi adalah sikap saling menghargai, menerima serta menghormati keragaman budaya dan perbedaan berekspresi, maka Alquran merupakan kitab suci yang secara nyata memberikan perhatian terhadap toleransi. Demikian ungkap Yohanan Freedmann, seorang Guru Besar Studi Islam di Universitas Hebrew, Jerussalem.

Contoh ayat Alquran yakni surat al-Baqarah: 62 (penafsirannya masih menjadi perdebatan antara mufassir tekstual dan kontekstual) yang intinya menurut Hamka (1967:181-183) bahwa orang Muslim, Yahudi, Kristen dan Sabian yang beriman kepada Tuhan, hari akhir dan beramal saleh, akan mendapatkan imbalan yang setimpal di hari perhitungan nanti.

Di lain ayat, Alquran menyebut bahwa di kalangan ahlul-kitab, terdapat orang-orang saleh. Terjemahan ayatnya; "Mereka itu tidak sama; di antara ahlul kitab itu ada golongan yang konsisten, mereka membaca ayat-ayat Tuhan pada beberapa waktu di malam hari, mereka juga bersujud. Mereka beriman kepada Tuhan dan hari akhir, menyuruh kepada kebaikan, dan mencegah dari yang mungkar, dan bersegera kepada pelbagai kebajikan; mereka itu termasuk orang-orang yang saleh". (Q.S. Ali Imran: 113-114).

Bila dibaca secara "critical thinking”, dapat dikatakan bahwa Islam (Alquran) telah memberikan simpati yang amat luar biasa terhadap ahlulkitab. Secara historis, tatkala ayat yang senada dengan ayat ini (misalnya surat 3: 199) diturunkan, sudah terdapat fakta keragaman agama, sekaligus keragaman pemeluknya. Mereka hidup berbaur dengan umat Islam. Sebagian mereka diapresiasi dengan sangat mulia oleh Alquran, tapi juga sebagiannya dikecam karena melakukan kezaliman. Terhadap kelompok yang zalim, Alquran mengajarkan untuk bertindak defensif dalam rangka menjaga kehormatan sebagaimana difirmankan Allah dalam Alquran (QS. 29: 46):

"Dan janganlah kamu berdebat dengan Ahli kitab, melainkan dengan cara yang paling baik, 
kecuali dengan orang-orang zalim di antara mereka, dan Katakanlah: "Kami Telah beriman kepada (kitab-kitab) yang diturunkan kepada kami dan yang diturunkan kepadamu; Tuhan kami dan Tuhanmu adalah satu; dan kami Hanya kepadaNya berserah diri".

Selanjutnya, Alquran, Surat Ali Imran ayat 110 juga menyatakan:

"Kamu adalah umat yang terbaik yang dilahirkan untuk manusia, menyuruh kepada yang ma'ruf, dan mencegah dari yang munkar, dan beriman kepada Allah. sekiranya ahli Kitab beriman, tentulah itu lebih baik bagi mereka, di antara mereka ada yang beriman, dan kebanyakan mereka adalah orang-orang yang fasik.

Dari kutipan ayat di atas dapat ditarik kesimpulan bahwa Islam yang rahmat dan wasthiyah itu terwujud pada sikap dan perilaku berislam yang inklusif, humais dan toleran. Nurcholish Madjid (2001:47) memberikan sebuah pernyataan bahwa Islam merupakan agama terbuka (open religion). Sikap ini seharusnya lebih ditonjolkan dalam menyikapi pluralisme dan kebinekaan seperti Indonesia, dan seharusnya pula umat Islam tampil sebagai "mediator" atau penengah, adil dan fair dalam hubungan antar kelompok yang berbeda-beda. Selanjutnya, Nurcholis Madjid (dalam M. Deden Ridwan, 2002:101- 102) mengatakan pluralisme dan kebinekaan mestinya diterima dan dipahami sebagai sebuah fakta sosial (fitrah sosial) yang merupakaan sebuah ketetapan Tuhan. Di dalam Alquran terdapat sejumlah ayat tentang pluralisme dan kebinekaan, antara lain :

QS. 5: 48 ...untuk tiap-tiap umat diantara kamu, kami berikan aturan dan jalan yang terang. sekiranya Allah menghendaki, niscaya kamu dijadikan-Nya satu umat (saja), tetapi Allah hendak menguji kamu terhadap pemberian-Nya kepadamu, Maka berlomba-lombalah berbuat kebajikan. Hanya kepada Allahlah kembali kamu semuanya, lalu diberitahukan-Nya kepadamu apa yang Telah kamu perselisihkan itu,

QS.30: 22. Dan di antara tandatanda kekuasaan-Nya ialah menciptakan langit dan bumi dan berlain-lainan bahasamu dan warna kulitmu. Sesungguhnya pada yang demikan itu benarbenar terdapat tanda-tanda bagi orang-orang yang Mengetahui.

QS.49:13. Hai manusia, Sesungguhnya kami menciptakan kamu dari seorang laki-laki dan seorang perempuan dan menjadikan kamu berbangsa bangsa dan bersuku-suku supaya kamu saling kenal-mengenal. Sesungguhnya orang yang paling mulia diantara kamu disisi Allah ialah orang yang paling taqwa diantara kamu. Sesungguhnya Allah Maha mengetahui lagi Maha Mengenal.

Jika direnungkan ayat-ayat di atas mengandung ajaran tentang indahnya kebinekaan dan pluralitas, khususnya dalam hal agama. Namun demikian pada tataran faktual (umat agamaagama) tidak seindah seperti di dalam kitab suci, karena masih sering terjadi tindakan intoleran seperti: intimidasi, kekerasan, maupun penyerangan yang dilakukan oleh sekelompok orang 
dengan atas nama agama tertentu terhadap kelompok agama lain; bahkan dalam satu agama yang kebetulan beda aliran atau paham.

Zuhairi Misrawi (2012: 159)

mengatakan membangun masyarakat yang toleran tidak seindah membalikkan telapak tangan, mengingat sejarah manusia pada hakikatnya adalah sejarah intoleransi. Apalagi tentang agama dan terutama cara kita beragama menurut Budhy Munawar Rachman (2001:ix) sesungguhnya tidak lepas dari sejarah masa lalu. Ketika itu para teolog menyusun konsep paham agama dan mengekstrimkannya dalam suatu situasi yang non pluralis; bahkan intoleran, karena sering muncul klaim kebenaran keyakinannya, sementara yang lain dinilai salah dan sesat. Kenyataan tersebut mengundang pertanyaan yakni apakah kemudian kita selaku umat (islam-muslim) bersikap menerima apa adanya dari warisan masa lalu tersebut? Ataukah ada upaya untuk membangun toleransi dengan memegang teguh teks-teks kitab suci (Alquran dan Assunnah), tetapi juga melakukan penafsiran baru berdasarkan situasi kekinian? Jawabannya adalah harus tetap dilakukan penafsiranpenafsiran terbaru yang relevan dengan situasi kekinian dengan memegang teguh ide moral dari nash-nash tersebut. Barangkali ini sebuah pilihan dan jalan keluar yang lebih bijak, dan inilah sebuah ikhtiar yang harus diupayakan oleh para ahli tafsir masa kini.

Berdasarkan pandangan tersebut, sikap yang sebaliknya yakni ekslusivisme dan absolutisme secara otomatis ditolak atas nama Islam.
Dengan sikap inklusif dan toleran, Nurcholis Madjid mengatakan (via M. Deden, 2002:103) umat Islam dapat memberi tempat pada pluralisme dan kebhinnekaan, yang disertai ketulusan menerimanya secara positif-konstruktif sebagai rahmat Tuhan untuk memperkaya dan mendinamisasi interaksi budaya yang heterogen. Sikap seperti ini juga dinyatakan oleh Abdurrahman Wahid (Gus Dur) (via Koirul Anwar, Kompasiana.com/ 2012/06/30) bahwa untuk merespon persoalan terutama berkenaan dengan pluralisme. Islam merupakan agama yang "memayu hayuning bawono". Agama yang mampu menjadi pelindung, penyemarak gerak hidup pemeluknya tanpa harus tercabut dari jati diri pemeluk itu sendiri. Islam yang mengusung demokrasi, terbuka, egaliter dan kosmopolit, mampu menyerap kehidupan modern, namun tetap dalam bingkai nilai-nilai ke-Islaman.

Dalam konteks keber-Indonesiaan dan keber-Pancasilaan menurut Cak Nur, (2002: 103), Islam inklusif-toleran menerima dan menetapkan Pancasila sebagai landasan yang kukuh bagi pengembangan toleransi beragama dan pluralisme ke-Indonesiaan. Pancasila tidak bertentangan dengan Islam, melainkan sejalan dengan prinsipprinsip Islam (baca: Piagam Madinah). Pancasila menurut Hamka Haq (2009: 31) harus dipahami sebagai sebuah idiologi negara yang inklusifistik dan sangat cocok buat bangsa Indonesia yang heterogen dan pluralistik. Oleh karena itu, mengukuhkan Pancasila sesungguhnya adalah juga mengukuhkan Islam di bumi Indonesia. 
Keduanya, ibarat mata uang yang memiliki dua sisi yang sama.

\section{Islam Rahmah, Wasathiyah dan Pesan Damai}

Sebagaimana telah diutarakan di awal tulisan ini, bahwa agama pada hakikatnya membawa pesan damai atau misi perdamaian. Hal ini menurut Afif Abdul Fatah Tabbarah (1996: 17) sejalan dengan salah satu makna Islam yang diambil dari istilah سَلِّم (salima) dan آسنْلمَ (aslama) adalah الصلح والامنم (asshulhu wal amnu) yakni damai dan aman. Oleh karenanya tidak dibenarkan adanya tindakan anarkis atau kekerasan walau dengan mengatas-namakan agama. Islam dalam hal ini Alquran sangat menjunjung tinggi nilai-nilai tersebut yakni damai dan aman sebagaimana mufassir (ahli tafsir) Muhammad Thahir bin 'Asyur (tt: 168) perlu dihadirkan kembali di tengah krisis dan pelanggaran kemanusiaan, yang terkadang dilakukan dengan dalih atas nama dan membela agama (Islam). Oleh karena itu, segala perilaku yang bersifat kekerasaan dengan dalih apa pun termasuk atas nama membela agama, sesungguhnya tidak dibenarkan karena bertentangan dengan prinsipprinsip Islam yang cinta damai dan menebarkan kasih sayang. Rasulullah Saw bersabda:

.... فإفنشاء السلام / أفنشوا السلام بينكم .... الحديث "Sebarkan dan tebarkan (taburkan) aroma damai di antara kami sebagai jalan meraih derajat yang tinggi di sisi Allah SWT."

Islam dengan pesan menebarkan kedamaian tersebut telah menjadi ciri yang menonjol di masa keemasan Islam (abad 7-13 M). Umat Islam dapat hidup berdampingan dengan umat lain dalam suasana damai. Bahkan, dalam beberapa periode kekuasaan dinasti Abbasiyah ada sejumlah pejabat setingkat gubernur dan menteri adalah nonmuslim (baik Yahud, Nasrani dan bahkan Majusi), padahal saat itu Islam menjadi pusat peradaban dunia. Pada zaman Nabi Saw (periode Madinah), semua agama dapat hidup berdampingan dalam suasana damai dan toleransi tinggi. Hal ini dapat diketahui dari poin-poin Piagam Madinah yang merupakan sebuah konstitusi tertulis dan sistematis pertama kali ada di dunia. Demikian ungkap seorang sosiolog terkemuka Amerika Serikat Robert N. Bellah yang banyak dikutip sejumlah pakar ilmu sosial di Indonesia (via Bahtiar Effendi, 1999:76). Bahkan dalam kekuasaan Islam sebagaimana dinyatakan oleh Sayidina Ali ra, ada jaminan keselamatan, kenyamanan, perlindungan hukum terhadap harta dan jiwa mereka yang non muslim, sebagaimana kaum muslim sendiri Apa yang dikatakan oleh Sayidina Ali ra, secara eksplisit, maupun inplisit menurut Nurcholis Madjid (via Budhy Munawar, 2007:151-153) termuat dalam Khutbah Wada' Nabi Muhammad Saw yang intinya yakni menjunjung tinggi nilai-nilai kemanusiaan universal, menghargai manusia atas dasar prinsip egalitarianisme, demokratis, partisipatif, berkeadilan dan beradab serta menebarkan perdamaian.

Dalam konteks sejarah Islam Indonesia (baca Penyebaran Islam di Indonesia) Islam dengan cirinya yang toleran, inklusif dan mengedepankan/ 
menebarkan kedamaian, menjadikannya sebagai agama yang paling cepat berkembang dan paling cepat diterima oleh masyarakat Indonesia. Terbukti hingga kini Islam menjadi agama mayoritas masyarakat Indonesia. Walau demikian, warisan sejarah masa lalu yang terkait dengan agama selain Islam, sperti Hindu dan Budha dengan candinya yang megah, tetap tegak berdiri, bahkan dijaga, dirawat oleh umat Islam yang merupakan umat mayoritas di sekitar candi-candi tersebut. Jadi, dengan demikian Islam yang damai (mengedepankan kedamaian) sudah menjadi "merek paten". Islam Indonesia, walau belakangan ada sejumlah kasus seperti tindakan teror (terorisme) atas nama agama (baca Islam), yang dilakukan oleh segelintir orang, dan sudah barang tentu bukan representasi muslim Indonesia.

Muslim Indonesia adalah muslim moderat yang diwakili oleh dua ormas Islam terbesar yaitu Muhammadiyah dan NU. Keduanya menurut Dien Syamsuddin (1992:4) laksana burung merpati dengan kedua sayapnya menerbangkan Islam berpaham/bercorak Islam moderat (wasthiyah) khas Indonesia. Oleh karenanya gagasan tentang Islam rahmah dan wasathiyah merupakan kekuatan terbesar di Indonesia, yang secara terus menerus (selalu) menemukan momentumnya untuk sampai di garda depan sebagai penyejuk dan penebar kedamaian. Ketika bangsa Indonesia mengalami situasi-situasi "kritis" dan krusial, Islam rahmah dan wasathiyah, inklussif - toleran dan damai, betul-betul cocok untuk bumi
Indonesia tercinta, karena telah teruji oleh dinamika sejarah.

\section{KESIMPULAN}

$\begin{array}{ccc}\text { Islam } & \text { yang dibawa Nabi } \\ \text { Muhammad } & \text { Saw adalah agama }\end{array}$ Rahmatan lil 'alamien, yang makna generiknya adalah kelembutan dan kasih sayang. Sebagai sebuah way of life yang komprehensif, Islam mengajarkan perlunya mengedepankan sikap Islam yang wasathiyah, inklusif, humanis, toleran dan damai dalam merespon "realitas kebinekaan Indonesia sebagai fakta sosial" dan mengelolanya secara positif-kontruktif untuk kebaikan, kemaslahatan bersama seluruh masyarakat Indonesia. Islam rahmatan, dan Islam moderat (wasathiyah), merupakan Islam khas Indonesia dan sudah teruji oleh sejarah dan oleh karenanya didalam berbagai situasi yang krusial, Islam dan muslim Indonesia tetap menemukan momentumnya sebagai agama yang mengedepankan sikap-sikap moderat, inklusif, humanis, toleran dan damai. Inilah Islam Indonesia masa lalu, masa kini dan masa depan. Islam dari masa ke masa. Wallahu 'alam.

\section{DAFTAR PUSTAKA}

Abdil Baqy, Muhammad Fuad,1981, alMu'jam al-Mufahrasy li al-Fadhil Qur'an al-Kariem, Beirut: Dar alFikr.

Abdullah, M.Amin, 2002, Study Agama, Normativitas atau Historisitas?, Yogyakarta: Pustaka Pelajar. Al-Qardhawi,Yusuf, 1996, Karakteristik Islam Kajian Analitik terj. Rofi' Munawwar, Surabaya: Risalah Gusti. 
Alquran, 1993, al-Karim dan

Terjemahannya, Jakarta: Intermasa.

Al-Qurthuby Al-Qurthuby, 1993, alJami' li-Ahkami Alquran, jilid VII, Beirut Lebanon: Dar al-Fikr.

Anwar, Khaerul, Pabumisasi Islam: Menuju Islam Rahmatan lil Alamin (Menapaki Alam pikiran gus Dur), Sosbud. Kompasiana.com/ 2012/06/30.

As-Shabuny, Muh. Ali, 1981 M/ $1401 \mathrm{H}$, Shafwatu at-Tafasir, jilid II, Beirut Lebanon: Dar Alquran al-Karim, cet. II.

As-Syaukany, Muhammad Ali, tt, Fathul Qadir, juz III, Mustafa al-Babi alHalaby.

At-Thabary, Muhammad bin Jarir, tt, Tafsir Thabary, jilid VII, Beirut: Dar al-Fikr. dan At-Thabary, Abu Ali al-Fadhil, 1992, Majma alBayan Fi at-Tafsir Alquran, juz III, Beirut Lebanon: Dar Ihya atTurats al-Arabiya, cet. I.

Effendi, Bahtiar, 1999, Wawasan Alquran tentang Masyarakat Madani: Menuju Terbentuknya Negara Bangsa yang Modern, dalam Jurnal Pemikiran Islam Paramdina vol. 1 no. 2, Jakarta: Paramadina.

Freedman, Yohanan, 2003, Tolerance and Caercion in Islam; Interfaith Relations in The Muslim Tradition, Cambridge University Press, United Kingdom.

Hamka, 1967, Tafsir al-Azhar, Juz I, Jakarta: Pembimbing Masa.

Haq, Hamka, Islam Rahmah Untuk Bangsa, Jakarta : RM BOOKS, 2009, hal. 31.

Hourani,Albert, Sejarah Bangsa Bangsa Muslim, terj. Irfan Abubakar, Bandung: Mizan Pustaka, 2004, bab 1.

Madjid, Nurcholish, 2001, Pluralisme Agama Kerukunan dalam Keberagamaan, Jakarta: Kompas.
Misrawi, Zuhairi, 2012, Alquran Kitab Toleransi; Tafsir Tematik Islam Rahmatan lil-Alamin, Jakarta: Pustaka Oasis.

Munawwir, A.W., 1997, Kamus Al Munawwir Arab-Indonesia, Surabaya: Pustaka Progressif.

Rachman, Budhi Munawar, 2001, Islam Pluralis: Wacana Kesetaraan Kaum Beriman, Jakarta: Paramadina. , 2007, Islam dan Pluralisme Nurcholish Madjid, Jakarta: Paramadina dan LSAF.

Ridwan, M Deden, 2002, Gagasan Nurcholish Madjid Neo Moderisme Islam; Dalam Wacana Tempo dan Kekuasaan, Yogyakarta: Belukar Budaya.

Shihab, Alwi,2001, Islam Inklusif: Menuju Sikap Terbuka Dalam Beragama, Bandung: Mizan.

Shihab, M. Quraish, 2002, Tafsir AlMishbah vol.1, Jakarta: Lentera Hati.

Syamsuddin, Din, 1992, "Tanggapan Terhadap Abdurrahman Wahid; Masalah Kepemimpinan umat Islam" dalam Jawa Pos, 26 Agustus 1992, Surabaya.

Tabbarah, Afif Abdul Fatah, 1966, Ruhu ad-Dien al-Islamy, Beirut Lebanon: Dar al-ilmi lilmalayin.

Thahir bin Asyur, Muhammad, tt, Tafsir al-Tahrir wa al-Tanwir, Tunisia: Dar Sahnoun Li anNasyr wa al-Tauzi.

Wahidin, Khaerul, 1987, Mengangkat Citra Diri Umat Islam, dalam Beragama di Abad 21, Editor: A. Syafi'i Mufid, Jakarta: Zihrul Hakim,

Watt,W.Montgomery, 1984, Muhammad Nabi dan Negarawan, terj. Johan Effendi, Jakarta: Kuning Mas,

Yulia Purnama, 2012, Muslim.or.id alQwa/islam rahmatan lilalamin.html/ 06 November. 


\section{UCAPAN TERIMA KASIH}

Redaksi Jurnal Humanika mengucapkan terima kasih atas partisipasi dan kesediaan Mitra Bestari untuk Volume. 15. Nomor. 1. September 2015, kepada;

Ajat Sudrajat (Universitas Negeri Yogyakarta) untuk artikel

1. "Islam Rahmah dan Wasathiyah (Paradigma Keberislaman Inklusif, Toleran dan Damai)" (Abd. Malik Usman)

2. "Etika Sosial dalam Kerukunan Umat Beragama (Studi Kasus di Desa Kotesan Kecamatan Prambanan Kabupaten Klaten Jawa Tengah)” (Andy Dermawan dan Zunly Nadia)

3. "Mencari Model Pendidikan Karakter" (Suparlan)

Suranto Aw (Universitas Negeri Yogyakarta) untuk artikel

1. "Persepsi Masyarakat Kotagede terhadap Pengunaan Media Komunikasi oleh Organisasi Forum Joglo untuk Pelestarian Budaya di Kotagede Yogyakarta” (Choirul Fajri)

2. "Implikasi Budaya Organisasi terhadap Pola Perilaku Komunikasi Kelompok Tani Sumber Rejeki” (Mariana Ulfah dan Siti Chotijah)

3. "Model Komunikasi "Wom” sebagai Strategi Pemasaran Efektif” (Dani Fadillah)

Yayan Suryana (Universitas Islam Negeri Sunan Kalijaga Yogyakarta) untuk artikel

1. "The Dialectics of Javanese and Islamic Cultures: an Introduction to Kuntowijoyo’s Thought” (Pradana Boy ZTF) 